\title{
Microstructural characteristics of TiC-reinforced composite coating produced by laser syntheses
}

\author{
Xiaolei $\mathrm{Wu}^{\mathrm{a})}$ \\ Laboratory for Nonlinear Mechanics of Continuous Media, Institute of Mechanics, \\ Chinese Academy of Sciences, Beijing 100080, People's Republic of China
}

(Received 9 December 1998; accepted 16 April 1999)

\begin{abstract}
An in situ method has been developed to produce a Ni alloy composite coating reinforced by in situ reacted and gradiently distributed $\mathrm{TiC}$ particles by one-step laser cladding. The dispersed, ultrafine TiC particles in the coating are observed. Most of TiC particles, evidently with a gradient distribution, are uniformly distributed within interdendritic regions due to the trapping effect of advanced solid-liquid interface. $\mathrm{The} \mathrm{TiC} / \gamma-\mathrm{Ni}$ interface is clean and free from deleterious surface reactions. The microhardness of the coating also has a gradient variation, with the highest value being $1250 \mathrm{Hv} 0.2$.
\end{abstract}

Ceramic particle-incorporation to provide a metal matrix composite (MMC) coating by laser cladding is a newly developed technique, in which the alloy powders of a desirable composition and a thin surface layer of the substrate materials are simultaneously melted and then rapidly solidified to form a dense coating that is metallurgically bonded to the base material. Some ceramicalloy systems, such as $\mathrm{SiC} / \mathrm{Co}-\mathrm{Cr}-\mathrm{W}, \mathrm{WC} / \mathrm{Ni}-\mathrm{Cr}-\mathrm{Si}-\mathrm{B}$, and $\mathrm{TiC}(\mathrm{TiN}, \mathrm{TiB}) / \mathrm{Ni}$-based alloys, synthesized on traditional substrate materials, have been studied. ${ }^{1-3}$

The aim of this communication is to synthesize an in situ $\mathrm{TiC}$ dispersoid in a $\mathrm{Ni}$ alloy coating. A new method of in situ formation of TiC with a gradient distribution by one-step laser cladding is proposed. TiC particles are introduced by an in situ reaction of titanium and graphite during a laser clad process, instead of TiC particles being directly added into the laser molten pool.

A power mixture of $\mathrm{Ni}$ alloy, titanium (99.7\% purity), and crystalline graphite $(99.5 \%$ purity) is used as the coating alloy. The volume fraction of titanium-graphite powders is $30 \%$. The titanium-carbon powder ratio corresponds to that of stoichiometric TiC. The average sizes of titanium and graphite powders are 2 and $4 \mu \mathrm{m}$, respectively. The Ni alloy powder possesses an average size of $28 \mu \mathrm{m}$, and its chemical composition (wt\%) is $16 \mathrm{Cr}, 3.5 \mathrm{~B}, 4.5 \mathrm{Si}, 0.8 \mathrm{C}$, and the balance is nickel. The substrate material is $5 \mathrm{CrMnMo}$ steel in a quenched and tempered condition.

Laser cladding is carried out with a $3-\mathrm{kW}$ continuous wave $\mathrm{CO}_{2}$ laser to produce a series of single clad tracks without overlap. The processing parameters are $4-15 \mathrm{~mm} / \mathrm{s}$ beam scanning speed, 3-mm beam diameter and 2-kW

a)e-mail: xlwu@cc5.imech.ac.cn laser power. The mixed powders are painted on the substrate with a thickness of about $0.8 \mathrm{~mm}$. Surface oxidation is prevented by argon.

The morphology, microstructure, and interface structure are observed with a Neuphot21 optical microscope, a Hitachi S570 scanning electron microscope (SEM), a Philips CM12 transmission electron microscope (TEM), and a Hitachi 9000 high-resolution electron microscope (HREM). The volume fraction of $\mathrm{TiC}$ particles in the coating is measured by a computerized image analysis method. Microhardness measurements are obtained with a Vickers hardness tester using a 0.2-kg load.

Figure 1 shows the optical micrograph of a cross section of the composite coating. The bond area between the clad coating and the substrate is an 8 - $\mu$ m-thick thin band of planar growth. The clad coating has a maximum thickness of about $820 \mu \mathrm{m}$ and is free of pores and cracks, which means an excellent metallurgical bond has been created between the coating and the substrate.

The growth morphology of the rapidly solidified coating depends mainly on the temperature gradient and the solidification rate. ${ }^{4}$ From the coating-substrate interface to the top surface of the coating, the morphology is successively a planar front, followed by cells and dendrites, consistent with the decreased temperature gradient and increased solidification rate. The planar, cellular, dendritic phases are FCC $\gamma-\mathrm{Ni}$ austenite. The interdendritic eutectic consists of $\gamma-\mathrm{Ni}$ and $(\mathrm{Fe}, \mathrm{Cr})_{23} \mathrm{C}_{6}$ carbides. X-ray diffraction shows that phases of the coating consist of $\gamma-\mathrm{Ni}, \mathrm{TiC},(\mathrm{Fe}, \mathrm{Cr})_{23} \mathrm{C}_{6}, \mathrm{Ni}_{5} \mathrm{Si}_{2}$, and $\mathrm{Cr}_{2} \mathrm{~B}$, without the existence of $\mathrm{Ni}-\mathrm{Ti}$ binery system intermetallic phases. The detailed microstructural analyses by TEM and x-ray diffraction are reported elsewhere. ${ }^{5,6}$ The results are in agreement with other studies in similar Ni alloy laserclad coatings. ${ }^{2,3}$ 
Figure 2 shows the distribution of TiC particles formed in situ on a microscale relevant to various growth morphologies of the Ni alloy. In the optical micrograph of Fig. 2(a), the specimen is etched with different etching reagents for the purpose of evidently revealing the cellular growth morphology of the $\mathrm{Ni}$ alloy and $\mathrm{TiC}$ particles. It is observed that $\mathrm{TiC}$ particles are uniformly distributed. Figure 2(b) shows a SEM micrograph of TiC particles with deep etching in the dendrite growth zone, where the solidification speed of the advancing solidliquid interface increases. A large amount of TiC particles are uniformly distributed in interdendritic regions, which means that $\mathrm{TiC}$ particles have been trapped by the rapidly moving solid-liquid interface. The size of $\mathrm{TiC}$ particles is on order of hundreds of nanometers. Additionally, the volume fraction of $\mathrm{TiC}$ particles in the dendritic zone is clearly enhanced compared with that in the cellular zone. The rapid movement of the solid-liquid interface limits the particle pushing effect and brings about a uniform distribution. In addition, rapid solidification also effectively decreases particle coarsening, which is detrimental to the structure-sensitive properties of composites.

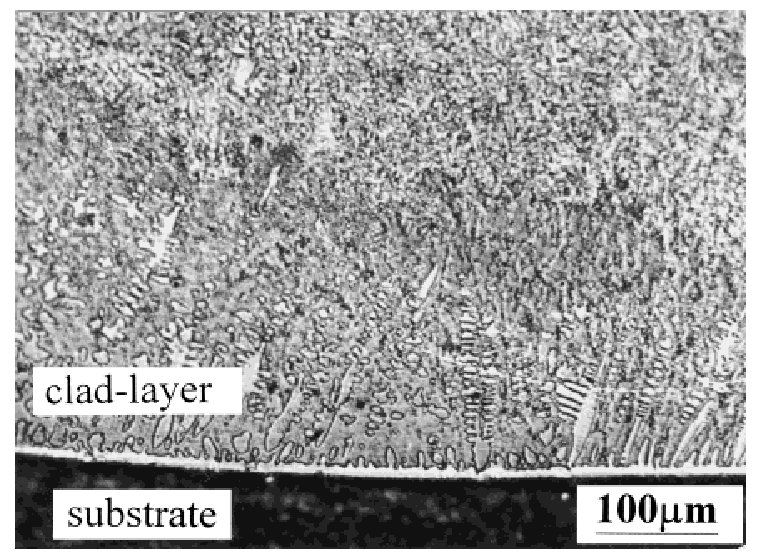

FIG. 1. Optical morphology showing transverse section of the coating.

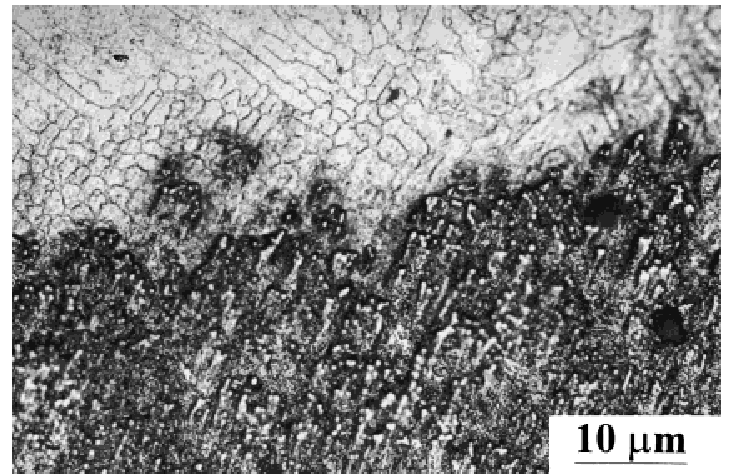

(a)
Figure 3 is the bright-field TEM micrograph showing TiC particles formed in situ in eutectic $\gamma-\mathrm{Ni}$ austenite. The particles are uniformly distributed.

Figure 4 is the HREM image illustrating the phase interface between $\mathrm{TiC}$ and $\gamma-\mathrm{Ni}$ austenite. It is noted that the interface remains clean and free from gas absorption, oxidation, and other deleterious surface reactions. Because of the high solidification speed and the high cooling speed, the interface reaction between the particle and the molten alloy is restrained to a large extent. This is one of main advantages of interfaces generated in situ. This clean interfacial structure is consistent with that obtained by other in situ processes. ${ }^{7}$

In the present method, $\mathrm{TiC}$ reinforced phases are introduced into the metal matrix by direct reaction. Therefore, the reinforced phase reacted in situ may be more compatible with the matrix, and the phase interface may be cleaner than composites produced conventionally. Meanwhile, because the precipitates formed in situ are often ultrafine and thermally stable, the composite matrix has sufficient strength to transfer stress.

The beam scanning speed has a key effect on the microdistribution of TiC particles, as shown in Fig. 5. Most $\mathrm{TiC}$ particles segregate between dendrite arms because of the solute pushing effect at a beam scanning speed of $4 \mathrm{~mm} / \mathrm{s}$. Furthermore, it is important to note that in the experimental range investigated, there exists a critical beam scanning speed, $8 \mathrm{~mm} / \mathrm{s}$, which corresponds to the transition of particle distribution from trapping to pushing by the advancing solid-liquid interface.

The microdistribution of particles depends mainly on the interaction between particles and the advancing solidliquid interface. The interaction may lead to trapping or pushing of particles by the solid-liquid interface. Trapping may bring about a uniform distribution of particles within interdendritic regions, whereas pushing results in the segregation at regions finally solidified. The interaction between particles and the advancing solid-liquid interface has been studied under conditions of equilibrium thermodynamics, i.e., at a very low crystal

FIG. 2. Distribution of TiC particles formed in situ in (a) cellular and (b) dendritic growth zone at a $15-\mathrm{mm} / \mathrm{s}$ beam scanning speed. 
growth speed. ${ }^{8,9}$ Also, it is widely accepted that there exists a critical speed that corresponds to a transition from pushing to trapping.

The quantitative or qualitative criterion for such an interaction under rapidly solidified conditions has not been developed because of the complexity of thermal physics in a laser molten pool. Also, the size, morphology, volume fraction, and thermal conductivity of particles and flow and stickability of the matrix influence the

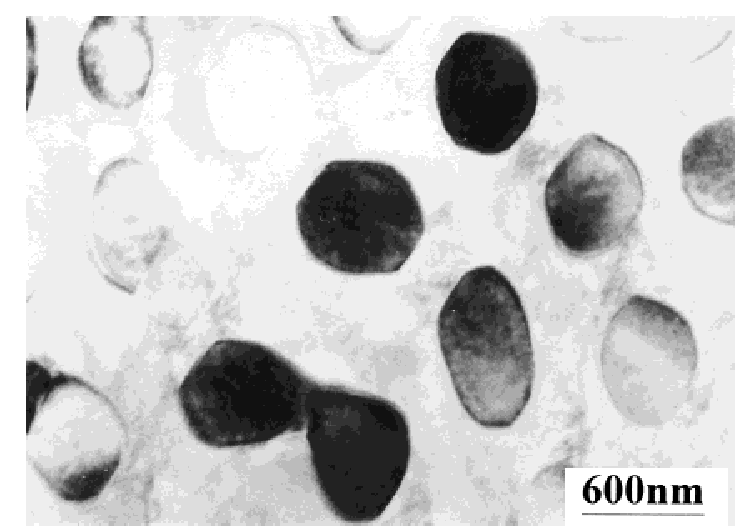

FIG. 3. Bright-field TEM micrograph showing morphology of TiC particles in the eutectic austenite at a $15-\mathrm{mm} / \mathrm{s}$ beam scanning speed.

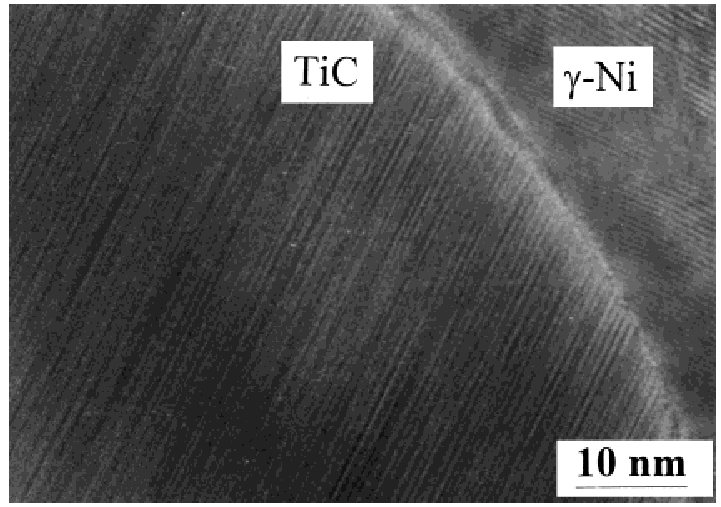

FIG. 4. HREM image showing $\mathrm{TiCp} / \gamma-\mathrm{Ni}$ interface.

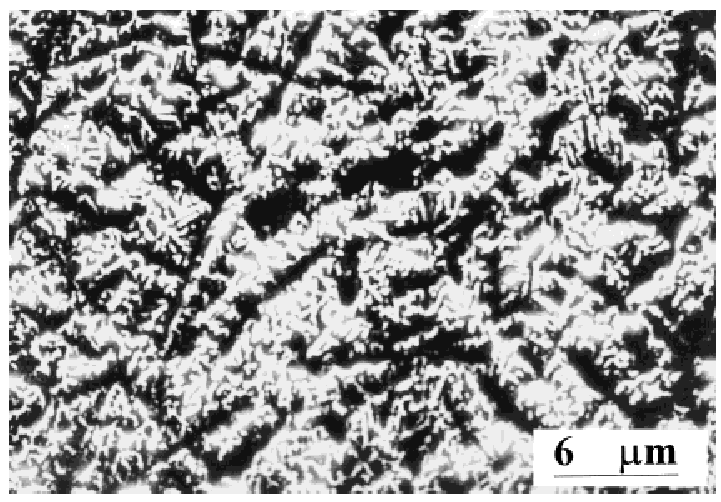

FIG. 5. SEM morphology showing segregation of TiC particles in dendritic zone at a $4-\mathrm{mm} / \mathrm{s}$ beam scanning speed. particle pushing effects. However, an increase in the local interface solidification speed, which is relevant to the beam scanning speed, is considered to have an important effect to realize particle trapping. Ehrstrom and $\mathrm{Kool}^{10}$ and $\mathrm{Li}^{11}$ pointed out that increasing the solidification speed and the cooling speed may weaken or even suppress the particle pushing effect in rapid solidification processing of composites. Fulcunaga et al., ${ }^{12}$ confirmed that, under the condition of rapid solidification, there exists a critical speed at which the transition from pushing to trapping occurs. From Fig. 2 and Fig. 5, it can be observed that increasing the beam scanning speed has a key effect on restraining the solute pushing effect.

It is observed, based on image analyses, that the volume fraction of $\mathrm{TiC}$ particles possesses a gradient distribution as a function of the coating depth (Fig. 6). The volume fraction of $\mathrm{TiC}$ particles changes from $1.86 \%$ at the bottom to $38.4 \%$ at the top surface of the coating. The average volume fraction of $\mathrm{TiC}$ in the whole coating is about $22.6 \%$, which is smaller than that of the original content in the mixture powder.

The relative low density of TiC compared with that of the $\mathrm{Ni}$ alloy may cause a gradient distribution on a macroscale. The differential-density-driven particle movement was also found in previous studies, ${ }^{13,14}$ where the particles tended to segregate to the upper region in the particle-reinforced composite coating. Hu et al., ${ }^{14}$ pointed out that whenever liquid viscosity and time allow, there will be ceramic particulate movement due to the relative densities of components. Additionally, the convective flow in the liquid will have its effect on the movement of the ceramic particulate. The forces and flow patterns resulting from surface tension gradients undoubtedly will strongly influence the distribution of ultrafine ceramic reinforcements formed in situ.

As is well known, the cladding coating often possesses different microstructural, physical, and mechanical characteristics from the substrate materials. As a result, the coating/substrate interface becomes the main failure place because of large stress concentration. The function-

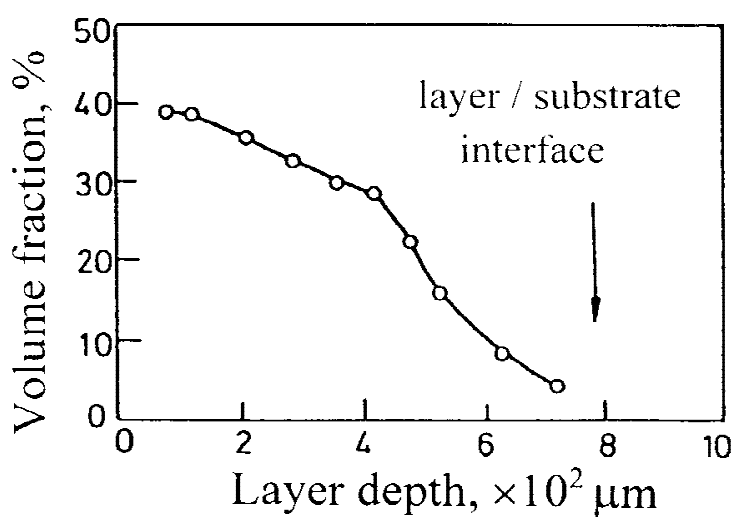

FIG. 6. Gradient distribution of TiC particles with coating depth. 


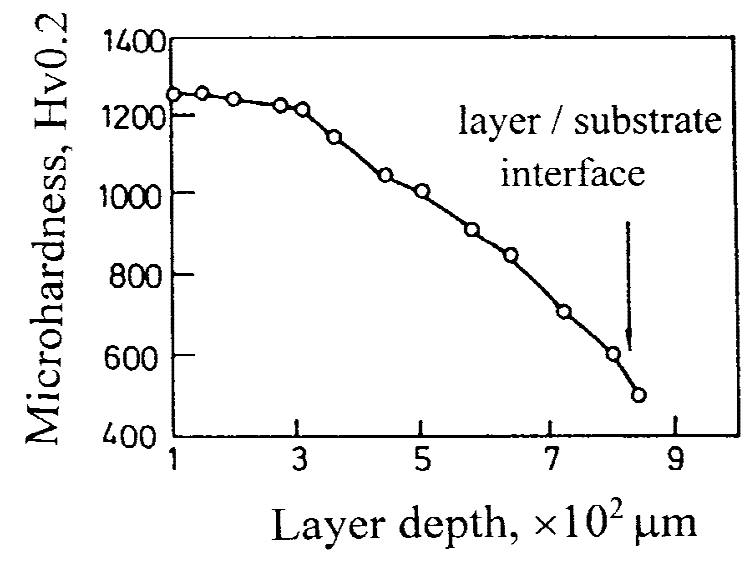

FIG. 7. Microhardness variation with coating depth.

ally gradient material (FGM), in which the composition, structure, and property vary continuously as a function of position, is pursued in order to avoid problems due to the interface. Recently, high-power $\mathrm{CO}_{2}$ lasers have been used to produce the functionally gradient coating (FGC) by successive deposition of several cladded coatings superimposed in a direction normal to the substrate, Jasim et al., ${ }^{15}$ obtained a FGC by three vertically overlapping laser-processed tracks, in which the proportion of $\mathrm{SiC}$ reinforcement increased in steps from 10 to $50 \mathrm{vol} \%$. Abboud and $\mathrm{West}^{16}$ also produced FGCs on $\mathrm{Ti}-\mathrm{Al}$ and $\mathrm{Ni}-\mathrm{Al}$ substrates by deposition of superimposed layers with various feed rates. However, the above multilayer coatings consist of essentially discrete layers rather than a smooth gradient of composition and structure. Also, there exist sharp demarcations between coatings, which create sudden changes in mechanical properties across the whole coating.

Figure 7 illustrates the hardness variation of a cross section of the coating as a function of the depth. It is observed that the microhardness also had a gradient distribution, consistent with the volume distribution of TiC particles. The highest hardness is $1250 \mathrm{Hv} 0.2$ at the coating surface.
In summary, a new in situ method has been developed to produce composite coatings by laser cladding. It is observed that the reinforced ultrafine, dispersed, and gradiently distributed $\mathrm{TiC}$ particles are formed in situ. There exists a critical beam scanning speed that corresponds to the transition from pushing to trapping of particles by an advancing solid-liquid interface. The microhardness of the coating also reveals a gradient variation with the highest value $1250 \mathrm{Hv} 0.2$ at the surface of the coating.

\section{ACKNOWLEDGMENTS}

The research was supported by the Major Research Foundation of Chinese Academy of Sciences under Grant KY951-Al-601-03, Key Foundation of Natural Science of China under Grant 59836220, and Postdoctoral Research Foundation of China under Grant 4868; their support is gratefully acknowledged.

\section{REFERENCES}

1. J.H. Abboud and D.R.F. West, J. Mater. Sci. 27, 420 (1992).

2. K.P. Kooper, SPIE-Int. Soc. Opt. Eng. 42, 957 (1988).

3. J.D. Ayers and T.R. Tucker, Thin Solid Films 73, 201 (1980).

4. A. Frenk and W. Kurz, Lasers Eng. 1, 193 (1992).

5. X.L. Wu and G.N. Chen, Acta Metall. Sinica 34, 1284 (1998).

6. X.L. Wu and G.N. Chen, Trans. Heat Treatment Metals 18, 1 (1998).

7. T.J. Langan and J.R. Pickens, Scr. Metall. Mater. 25, 1587 (1991).

8. D.R. Uhlmann, B. Chalmers and K.A. Jackson, J. Appl. Phys. 35, 2986 (1964).

9. S.N. Omenyi, A.W. Neumann, and C.J. van Oss, J. Appl. Phys. 52, 789 (1981).

10. J.C. Ehrstrom and W.H. Kool, J. Mater. Sci. 23, 3195 (1988).

11. B.Q. Li, JOM 8, 13 (1995).

12. H. Fulcunaga, S. Komatsu and Y. Kanoh, Bull. Jpn. Soc. Mech. Eng. 26, 1814 (1983)

13. G. Abbas and D.R.F. West, Wear 143, 353 (1992).

14. C. Hu, L. Barnard, S. Mridha, and T.N. Baker, J. Mater. Process. Tech. 58, 87 (1996).

15. K.M. Jasim, R.D. Rawlings, and D.R.F. West, J. Mater. Sci. 28, 2820 (1993).

16. J.H. Abboud and D.R.F. West, J. Mater. Sci. Lett. 13, 457 (1994). 